Rev. Bras. Cir. Cardiovasc.,

5(2): 86-98, 1990.

\title{
Plástica mitral
}

\author{
Domingo M. BRAILE*, Roberto V. ARDITO*, Grácia Helena PINTO*, José Luiz Verde dos SANTOS*, Marcos \\ ZAIANTCHICK*, Dorotéia Rossi S. SOUZA*, Rubens THEVENARD*
}

RBCCV 44205-111

BRAILE, D. M.; ARDITO, R. V.; PINTO, G. H.; SANTOS, J. L. V.; ZAIANTCHICK, M.; SOUZA, D. R. S.; THEVENARD, R. - Plástica mitral. Rev. Bras. Cir. Cardiovasc., 5(2): 86-98, 1990.

RESUMO: Foram estudados 101 pacientes submetidos a plástica da valva mitral em seis anos, com seguimento de $100 \%$. Entre eles, 36 eram do sexo masculino e 65 do sexo feminino, com idade variando de dois a 62 anos $(M=28 \pm 16,4)$. Desses, $57(56,4 \%)$ foram submetidos apenas a abordagem valvar mitral. Os demais foram submetidos a procedimentos associados, como plástica tricúspide $(9,9 \%)$, revascularização do miocárdio $(4,0 \%)$, entre outros. Não foi registrado óbito imediato. O índice de mortalidade tardia foi de $2 \%$ (AVC hemorrágico após cinco anos e septicemia), no primeiro ano. As complicaçôes não fatais foram representadas pela endocardite evidenciada em dois pacientes $(2 \%)$, sendo tratados e curados, e um paciente com reestenose mitral pós-plástica por reagudizaçāo da doença reumática. $\mathrm{O}$ estudo atuarial revelou um indice de $79,0 \pm 17,7 \%$ de sobrevida, um total de $76,3 \pm 17,8 \%$ de pacientes livres de complicaçōes, $80,0 \pm 17,9 \%$ de reoperaçōes, $100,0 \%$ livres de tromboembolismo. Os resultados ecodoplercardiográficos registraram que $89 \%$ dos pacientes evoluíram com ausência de insuficiência. Dos $11 \%$ restantes, $7,4 \%$ apresentram insuficiência mitral discreta, $2,4 \%$ moderada e $2 \%$ importante. De acordo com a classificaçāo da NYHA, os pacientes das classes III $(83,8 \%)$ e IV $(16,2 \%)$ passaram para as classes I $(33,3 \%)$, II $(60,6 \%)$, III $(4,1 \%)$ e IV $(2 \%)$. Os autores concluem que 0 anel de pericárdio flexível conforma-se perfeitamente com o anel valvar, nāo produz hemólise e se endoteliza completamente a médio prazo.

DESCRITORES: valva mitral, plastia; próteses valvulares cardiacas, biológicas, cirurgia.

\section{INTRODUÇÃO}

Para o perfeito funcionamento da valva mitral, é necessária a integridade funcional dos seguintes elementos anatômicos: parede atrial posterior esquerda, anel, cúspides, cordas tendíneas, músculos papilares e parede ventricular esquerda ${ }^{35}$. Tal interação pode ser alterada diante de distúrbios ocasionados por doenças congênitas ou adquiridas, entre elas doença reumática, infecçōes e doença cardíaca isquêmica. Essas afecçōes podem causar dilatação do anel valvar, hipoplasia da cúspide posterior, alongamento das cordas tendíneas e rotura das cordas anterior e/ou posterior ${ }^{18,32,36}$, tendo, como conseqüência, a insuficiência e/ou a estenose mitral.

Para a recuperação do funcionamento normal dé valva mitral, existem duas opçōes: a reconstrução, ou a troca valvar. Desde o início da cirurgia cardíaca, vários métodos de reparo da valva mitral foram empregados. Contudo, somente poucos demonstraram ter real valor.

A possibilidade de realização da plástica mitral foi, inicialmente, proposta por BRUNTON ${ }^{10}$, e 1902. No entanto, só em 1957 foi feita, por LILLEHEI et alii ${ }^{29}$, a primeira tentativa de se corrigir a insuficiência mitral pura por anuloplastia. Posteriormente, outras técnicas foram desenvolvidas, com destaque, por CARPENTIER et $a{ }^{\prime i} i^{13}$, na década de 70 . Empregando um anel protético rígido para a manutenção da área da cúspide anterior, diminuíam o tamanho anular total da reduçăo uniforme da cúspide posterior. Mais tarde, DURAN \& UBAGE ${ }^{23}$ propuseram o uso de uma prótese maleável, permitindo o movimento do anel durante a contração ${ }^{21}$.

A introdução de próteses e homoenxertos valvares ${ }^{8}$. ${ }^{41}$ provocou desinteresse pelas técnicas de reparo mitral.

Trabalho realizado no Instituto de Moléstias Cardiovasclar de São José do Rio Preto. SP, Brasil.

Apresentado ao 17: Congresso Nacional de Cirurgia Cardiaca. Belo Horizonte, MG, 6 e 7 de abril, 1990.

* Do Instituto de Moléstias Cardiovasculares de São José do Rio Preto.

Endereço para separatas: Domingo M. Braile. Rua Castela D'Água, 3030. 
BRAILE, D. M.; ARDITO, R. V.; PINTO, G. H.; SANTOS, J. L. V.; ZAIANTCHICK, M.; SOUZA, D. R. S.; THEVENARD, R. Plástica mitral. Rev. Bras. Cir. Cardiovasc., 5(2): 86-98, 1990.

Contudo, hoje, graças à evoluçāo das técnicas cirúrgicas e de proteção ao miocárdio, ressurge o interesse na conservação da valva mitral, principalmente considerando as complicaçōes que a troca valvar pode acarretar ${ }^{3,33}$, 37. Como conseqüência, o número de trocas valvares na doença mitral diminuiu, nos últimos anos, enquanto que o de reparo aumentou proporcionalmente ${ }^{15}$. No Brasil, essa técnica conta, principalmente, com o apoio de GREGORI et alii ${ }^{27}$, entre outros.

Este estudo apresenta a experiência com a técnica desenvolvida no Serviço IMC, com medidores do perímetro da cúspide anterior da valva mitral, e com uma prótese maleável e radiopaca de pericárdio bovino, para reforço e conformaçāo do anel posterior, reduzindo-o ao perímetro da cúspide anterior, levando ao ajustamento da valva.

\section{CASUÍSTICA E MÉTODOS}

De março de 1984 a novembro de 1989 , foram realizadas, no IMC, um total de 1317 cirurgias valvares. Dessas, $907(68,9 \%)$ abordaram a valva mitral, compreendendo $101(11,1 \%)$ plásticas, $249(30,9 \%)$ comissurotomias e $557(69,1 \%$ ) trocas (Quadro 1). Para o presente trabalho, foram considerados os 101 pacientes submetidos a plástica valvar mitral, com prótese maleável de pericárdio bovino implantada em anel posterior. Desses, $65(35,6 \%)$ eram do sexo feminino e $36(64,4 \%)$ do sexo masculino, com idade variando de dois a 62 anos, com 41 jovens ( $<=21$ anos) e 60 adultos ( $>21$ anos), com média de idade de $28,9 \pm 16,4$ anos.

A maioria dos pacientes $(77,2 \%)$ teve, como etiologia, a doença reumática causadora da lesão valvar, seguida da degeneração mixomatosa $(7,9 \%)$, da cardiopatia congênita $(5,9 \%)$, da endocardite bacteriana $(5,0 \%)$ e da lesão isquêmica (4,0\%) (Figura 1 ).
QUADRO 1

TOTAL DE CIRURGIAS VALVARES REALIZADAS NO IMC (1984-1989).

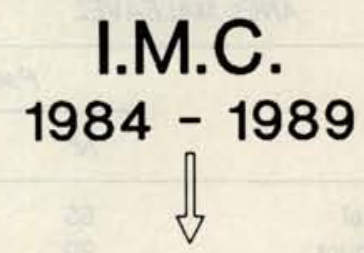

1317

Cirurgias Valvares<smiles>O=C=O</smiles>

907

Mitrais

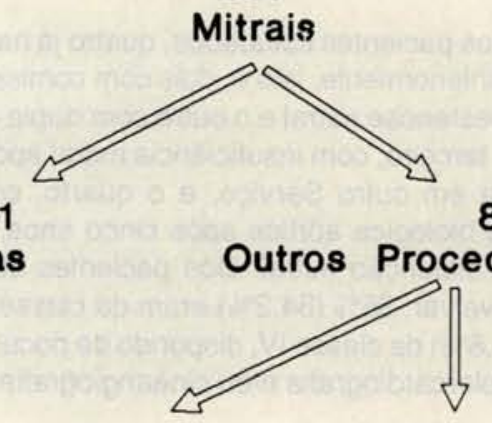

249

557

Comissurotomia

Trocas

As lesōes que determinaram o reparo valvar foram, principalmente, a insuficiência mitral pura, presente em 55 pacientes $(54,4 \%)$, a estenose mitral pura em 20 $(19,8 \%)$ e a dupla disfunção mitral em 17 pacientes $(16,8 \%)$. Os diagnósticos pré-operatórios e suas respectivas freqüências estão na Tabela 1.

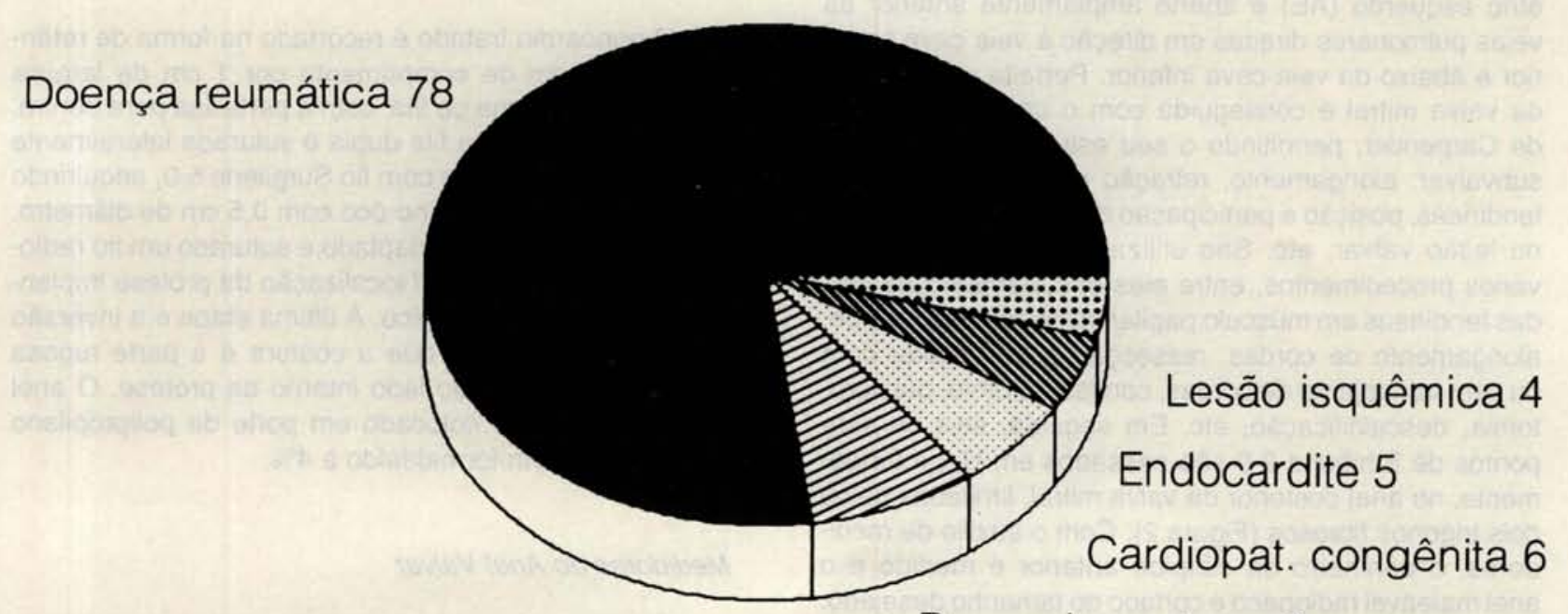

Fig. 1 - Causas das lesōes mitrais dos pacientes submetidos ao reparo valvar mitral. 
BRAILE, D. M.; ARDITO, R. V.; PINTO, G. H.; SANTOS, J. L. V.; ZAIANTCHICK, M.; SOUZA, D. R. S.; THEVENARD, R. Plástica mitral. Rev. Bras. Cir. Cardiovasc., 5(2): 86-98, 1990.

TABELA 1

DIAGNOSSTICO PRÉ-OPERATÓRIO DOS PACIENTES SUBMETIDOS A CIRURGIA DE REPARO VALVAR COM ANEL MALEÁVEL

\begin{tabular}{lrr}
\hline & \multicolumn{2}{c}{ Pacientes } \\
\cline { 2 - 3 } & $N$ & $\%$ \\
\hline Insuficiência mitral & 55 & 54,4 \\
Estenose mitral pura & 20 & 19,8 \\
Dupla lesão mitral & 17 & 16,8 \\
Endocardite tratada & 4 & 4,0 \\
Estenose mitral calcificada & 3 & 3,0 \\
Prolapso mitral & 2 & 2,0 \\
Total & 101 & 100,0 \\
\hline
\end{tabular}

Entre os pacientes estudados, quatro já haviam sido operados anteriormente, isto é, dois com comissurotomia, um com reestenose mitral e o outro com dupla disfunção mitral. Um terceiro, com insuficiência mitral após um ano da plástica em outro Serviço, e o quarto, com rotura de prótese biológica aórtica após cinco anos, apresentam dupla disfunçāo mitral. Dos pacientes submetidos ao reparo valvar, $85 \%(84,2 \%)$ eram da classe funcional III e $16(15,8 \%)$ da classe IV, dispondo de documentação por ecodoplercardiografia e/ou cineangiografia pré e pós cirurgia.

\section{Técnica Cirúrgica}

Estabelecida a circulação extracorpórea (CEC) por drenagem de ambas as cavas e perfusāo pela aorta, esta é pinçada com o início da infusão de cardioplegia sangüínea contínua modificada por cânula 12F, e medida da pressão com jelco n: 16. A temperatura corporal é mantida em $32^{\circ} \mathrm{C}$ e a miocárdica entre 22 e $25^{\circ} \mathrm{C}$. O átrio esquerdo $(\mathrm{AE})$ é aberto amplamente anterior às veias pulmonares direitas em direção à veia cava superior e abaixo da veia cava inferior. Perfeita visibilização da valva mitral é conseguida com o uso do afastador de Carpentier, permitindo o seu estudo e do aparelho subvalvar: alongamento, retração ou rotura de cordas tendíneas, posição e participação da musculatura papilar na lesão valvar, etc. São utilizados ganchos para os vários procedimentos, entre eles encurtamento de cordas tendíneas em músculo papilar ou na própria cúspide, alongamento de cordas, ressecção quadrangular com ou sem transplante de cordas, comissurotomia, papilarotomia, descalcificaçāo, etc. Em seguida, seis ou sete pontos de Ethibond 2-0 são passados em $U$, profundamente, no anel posterior da valva mitral, limitados pelos dois trígonos fibrosos (Figura 2). Com o auxilio de medidores, o perímetro da cúspide anterior é medido e o anel maleável radiopaco é cortado no tamanho desejado. Os pontos são passados de forma a "encolher" o anel valvar posterior. Os pontos são amarrados e o teste de suficiência é feito passando-se a sonda $12 \mathrm{~F}$ através da valva aórtica, até o ventrículo esquerdo, para injeção de sangue fornecido pela bomba de infusão cardioplégica. Qualquer anormalidade no aparelho subvalvar é facilmente corrigida, já que o anel de pericárdio bovino, sendo maleável, permite novas abordagens, mesmo após sua fixação. São realizados tantos testes quantos forem necessários, já que está sendo feita injeção de sangue do priming e não de soro. O AE é fechado com três fios de Prolene 3-0 e sua pressão é medida em coluna de água, permitindo a saída tranqüila de CEC e a avaliação do procedimento plástico sobre a valva mitral.

\section{Processamento do Pericárdio Bovino}

O pericárdio é coletado em frigoríficos, imediatamente após o abate dos animais, mantido e transportado em soluçāo hipertônica de $\mathrm{NaCl}$ a pH 7,4 a $4^{\circ} \mathrm{C}$. A limpeza é feita no laboratório nessa mesma solução, seguida da montagem do pericárdio em suporte, com posterior fixação em soluçāo de glutaraldeído a $0,5 \%$ por 15 dias a $4^{\circ} \mathrm{C}$ e três dias à temperatura ambiente, com trocas periódicas da solução. Após esse fase, o pericárdio é mantido em solução de formaldeído a $4 \%$, quando são realizados os testes de controle de qualidade, entre eles encolhimento, elongação, rotura, tensão superficial crítica, medida de espessura e histologia. São liberados apenas os pericárdios que preencherem os critérios previamente estabelecidos, com base em mínimos exigíveis. Esses testes permitem avaliar a atuação do glutaraldeído no curtimento do tecido, que deve conservar o alinhamento dos feixes colágenos sem alterar sua ondulação natural, proporcionando a devida elasticidade mecânica ao tecido.

\section{Contecção do Anel Maleável}

O pericárdio tratado é recortado na forma de retângulo com $8 \mathrm{~cm}$ de comprimento por $1 \mathrm{~cm}$ de largura e dobrado em forma de fita, com a parte lisa para dentro. Posteriormente, essa fita dupla é suturada lateralmente com pontos separados com fio Surgilene 5.0, adquirindo o aspecto de um tubo fino ôco com $0,5 \mathrm{~cm}$ de diâmetro. No seu fechamento, é adaptado e suturado um fio radiopaco, que permite a fácil localização da prótese implantada, ao exame radiológico. A última etapa é a inversão do tubo, de tal modo que a costura e a parte rugosa do pericárdio ficam do lado interno da prótese. $O$ anel pronto para uso é colocado em porte de polipropileno e conservado em formaldeído a $4 \%$.

\section{Medidores do Anel Valvar}

Com a intenção de possibilitar a medida exata da cúspide anterior, para a escolha correta do tamanho do 
BRAILE, D. M.; ARDITO, R. V.; PINTO, G. H.; SANTOS, J. L. V.; ZAIANTCHICK, M.; SOUZA, D. R. S.; THEVENARD, R. Plástica mitral. Rev. Bras. Cir. Cardiovasc., 5(2): 86-98, 1990.

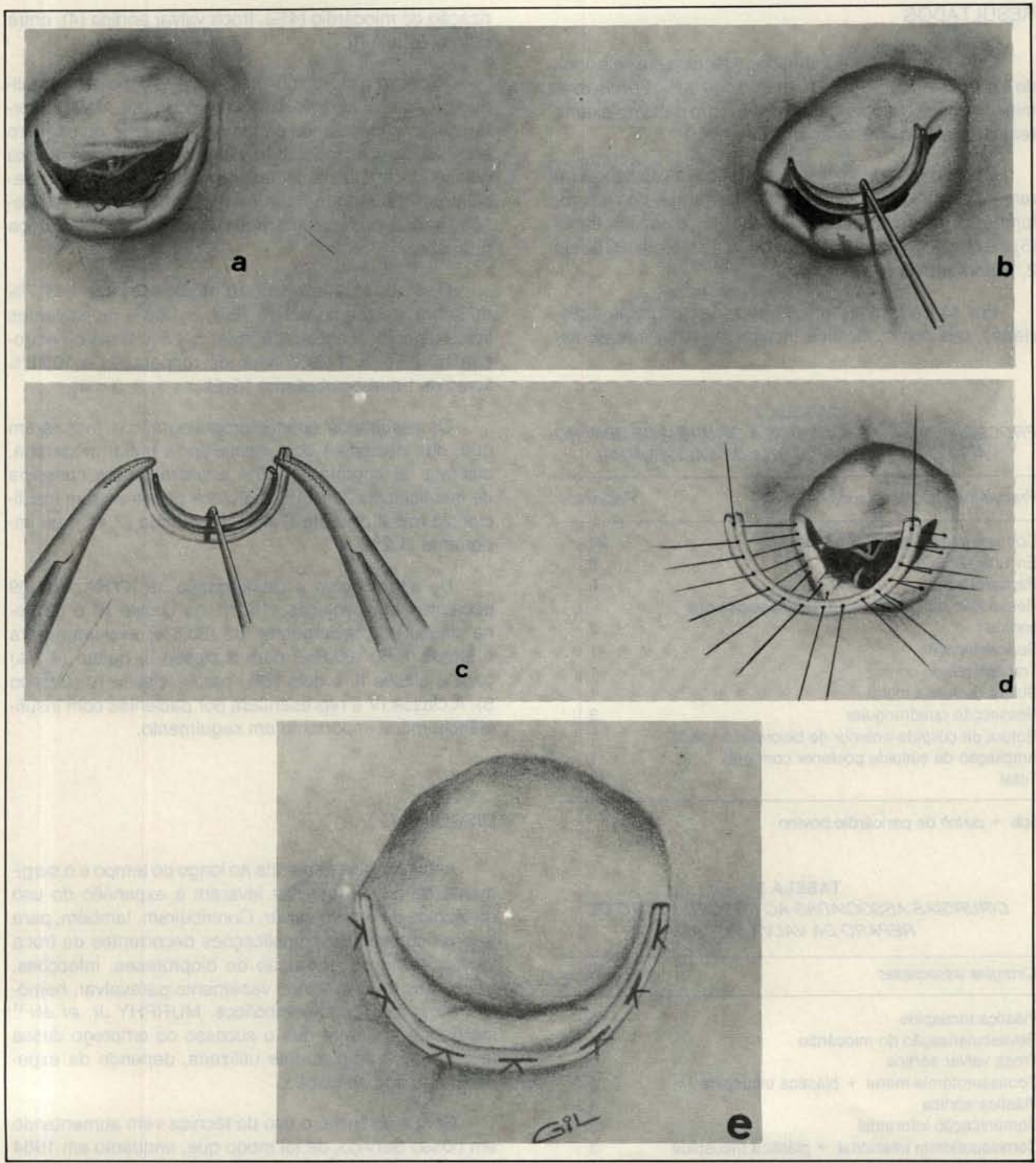

Fig. 2 - llustração esquemática mostrando a sequeência de abordagem valvar mitral por plástica. (a) valva mitral insuficiente; (b) medida do perímetro da cúspide anterior (medidor IMC-Bio); (c) ajuste do tamanho do anel maleável com o medidor escolhido; (d) passagem de pontos do anel valvar em " $U$ " limitados pelos trígonos fibrosos; (e) resultado final.

anel maleável, são utilizados medidores de aço inoxidável. São compostos por uma haste de $24 \mathrm{~cm}$ de comprimento, com $4,7 \mathrm{~mm}$ de diâmetro no centro e $1,6 \mathrm{~mm}$ nas extremidades, sustentando um semicírculo em cada uma das extremidades, ou seja, os medidores de anel. Portanto, os medidores apresentam-se aos pares nas medidas de $21 \mathrm{~mm}$ e $23 \mathrm{~mm}, 25 \mathrm{~mm}$ e $27 \mathrm{~mm}$ e 29 $\mathrm{mm}$ e $31 \mathrm{~mm}$. 
BRAILE, D. M.; ARDITO, R. V.; PINTO, G. H.; SANTOS, J. L. V.; ZAIANTCHICK, M.; SOUZA, D. R. S.; THEVENARD, R. Plástica mitral. Rev. Bras. Cir. Cardiovasc., 5(2): 86-98, 1990.

\section{RESULTADOS}

Os 101 pacientes submetidos à técnica em seis anos de experiência tiveram seguimento de $100 \%$. Foram examinados por ecodoplercardiografia, com o último exame realizado até seis anos após a cirurgia.

Os procedimentos associados sobre a valva totalizaram 47 ocorrências, com destaque para a comissurotomia (23), o encurtamento de cordas (9), a papilarotomia (5) e a ressecção quadrangular (3), registrados na Tabela 2 , juntamente com os demais.

Em 44 pacientes, foram realizadas cirurgias associadas, tais como: plástica tricúspide $(10 \%)$, revascula-

TABELA 2

PROCEDIMENTOS ASSOCIADOS A CIRURGIA DE REPARO VALVAR POR ANULOPLASTIA DE VALVA MITRAL

\begin{tabular}{lc}
\hline Procedimentos associados & Pacientes \\
\hline Comissurotomia anterior e posterior & 23 \\
Encurtamento de cordas & 9 \\
Papilarotomia & 5 \\
Ressecção quadrangular + transposição das & 2 \\
cordas & 1 \\
Descalcificação & 1 \\
Transplante de cordas & 1 \\
Sutura de fenda mitral & 3 \\
Ressecção quadrangular & 1 \\
Rotura de cúspide anterior de bioprótese valvar & 1 \\
Ampliação da cúspide posterior com ppb & 47 \\
Total & \\
\hline
\end{tabular}

$\mathrm{ppb}=$ patch de pericárdio bovino

TABELA 3

CIRURGIAS ASSOCIADAS AO PROCEDIMENTO DE REPARO DA VAL VA MITRAL

\section{Cirurgias associadas} Pacientes

Plástica tricúspide

Revascularizaçāo do miocárdio

Troca valvar aórtica

Comissurotomia mitral + plástica tricúspide

Plástica aórtica

Comunicação interatrial

Comissurotomia interatrial + plástica tricúspide

Comissutoromia mitral + plástica aórtica

Mixoma de átrio esquerdo

Plástica aórtica + plástica tricúspide

TV aórtica + alargamento aorta

Comissurotomia mitral + plástica tricúspide + TV

aórtica

Plástica aórtica + Ci ventric.

Comissurotomia mitral e tricúspide + plástica

Átrios ventriculares + comissurotomia

Total rizaçāo do miocárdio (4\%), troca valvar aórtica (4), entre outos (Tabela 3).

Não foi registrado óbito imediato. O índice de mortalidade tardia foi de $2 \%$, isto é, um óbito por AVC hemorrágico após cinco anos e um por septicemia no primeiro ano. As complicaçōes não fatais foram representadas pela endocardite bacteriana, evidenciada em dois pacientes $(2 \%)$, sendo tratados e curados, e uma reestenose mitral pós-plástica por reagudização da doença reumática.

O estudo atuarial revelou um índice de $79,0 \pm 17,7 \%$ de sobrevida e um total de $76,3 \pm 17,8 \%$ de pacientes livres de complicações, de 95,4 $\pm 4,5 \%$ livres de endocardite, $80,0 \pm 17,9 \%$ livres de reoperação e $100,0 \%$ livres de tromboembolismo (Gráficos 1, 2, 3 e 4).

Os resultados ecodoplercardiográficos mostraram que, dos pacientes com insuficiência mitral moderada, discreta ou importante, $89 \%$ evoluíram para ausência de insuficiência. Os $11 \%$ restantes apresentaram insuficiência mitral discreta $(7,4 \%)$, moderada $(2,4 \%)$, ou importante $(1,2 \%)$.

De acordo com a classificação da NYHA, dos 99 pacientes em evolução $(16,2 \%$ na classe IV e $83,8 \%$ na classe III, previamente), $33(33,3 \%)$ evoluíram para a classe I, $60(60,6 \%)$ para a classe II, quatro $(4,1 \%)$ para a classe III e dois $(2 \%)$ para a classe IV (Gráfico 5). A classe IV é representada por pacientes com insuficiência mitral importante em seguimento.

\section{DISCUSSÃO}

A experiência adquirida ao longo do tempo e o surgimento de novas técnicas levaram à expansão do uso da técnica de reparo valvar. Contribuíram, também, para isso as conhecidas complicaçōes decorrentes da troca valvar, como degeneraçāo de biopróteses, infecçōes, gradientes transvalvares, vazamento paravalvar, hemolise e eventos tromboembólicos. MURPHY Jr. et alii ${ }^{31}$ insistem em afirmar que o sucesso do emprego dessa técnica, hoje amplamente utilizada, depende da experiência de sua aplicação.

Com a vivência, o uso da técnica vem aumentando em nosso Serviço, de tal modo que, enquanto em 1984 foram realizados $32,6 \%$ de troca mitral e $2,6 \%$ de reparo, em 1989, de 356 cirurgias valvares realizadas, $19,1 \%$ foram de troca mitral e $9,8 \%$ de reparo. A frequêencia do uso dessa técnica tem sido, também, preocupação em outros Serviços ${ }^{11,} 38$.

Por outro lado, a nossa experiência com a prótese valvar de pericárdio bovino em posição mitral, em 11 anos de seguimento, tem sido, também, satisfatória, com $74,3 \%$ de sobrevida e $95,8 \%$ dos pacientes livres de eventos tromboembólicos, sem o uso de anticoagulan- 
BRAILE, D. M.; ARDITO, R. V.; PINTO, G. H.; SANTOS, J. L. V.; ZAIANTCHICK, M.; SOUZA, D. R. S.; THEVENARD, R. Plástica mitral. Rev. Bras. Cir. Cardiovasc., 5(2): 86-98, 1990.

\section{GRÁFICO 1}

CURVAS ATUARIAIS DE SOBREVIDA DE PACIENTE COM TROCA MITRAL NAS VALLVULAS DE PERICARDIO BOVINO E COM REPARO VALVAR EM 11 E 6 ANOS DE SEGUIMENTO, RESPECTIVAMENTE.

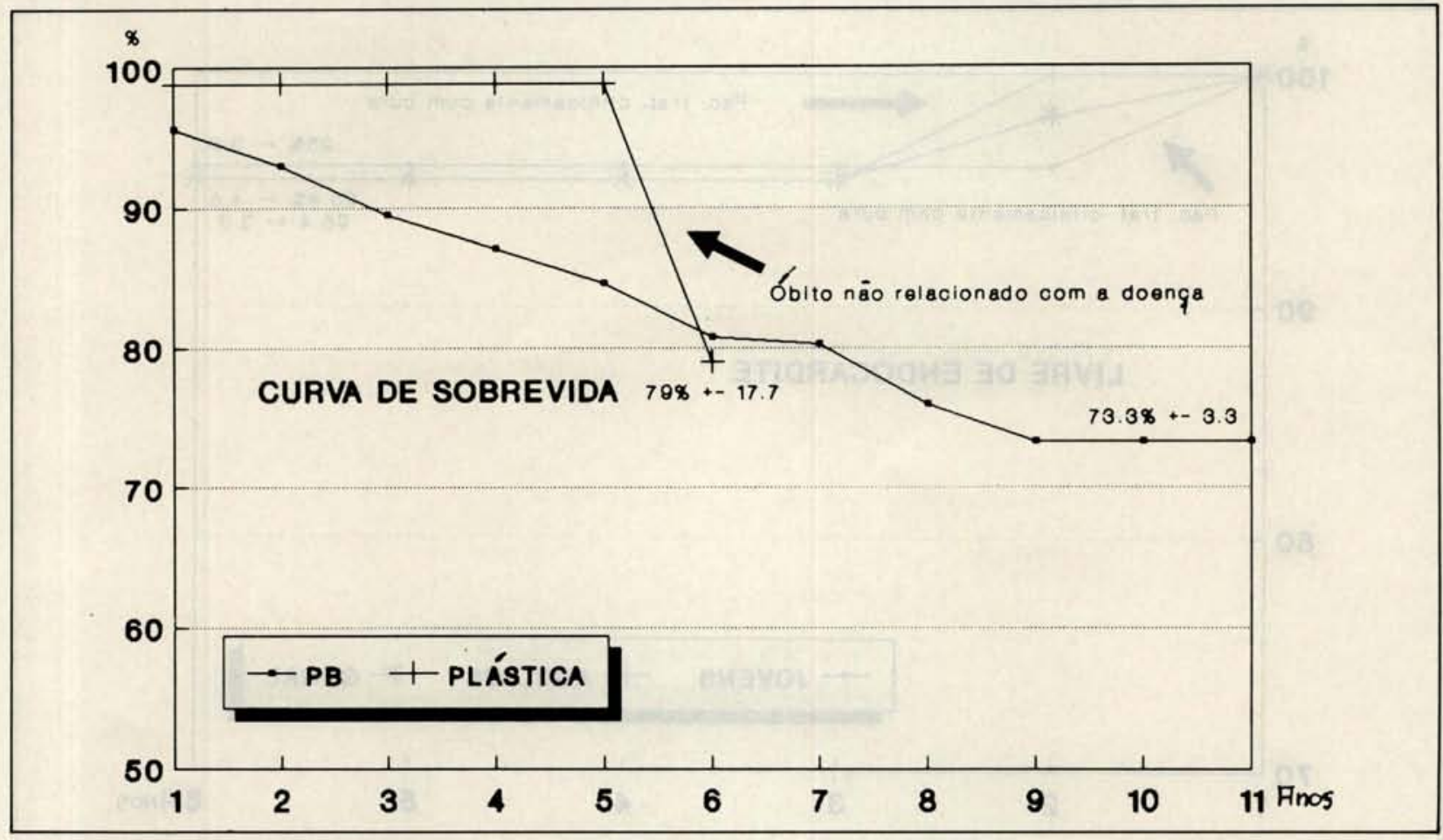

GRÁFICO 2

CURVAS ATUARIAIS DE PACIENTES SUBMETIDOS AO REPARO VALVAR LIVRES DE COMPLICACYAOO EM SEIS ANOS DE SEGUIMENTO.

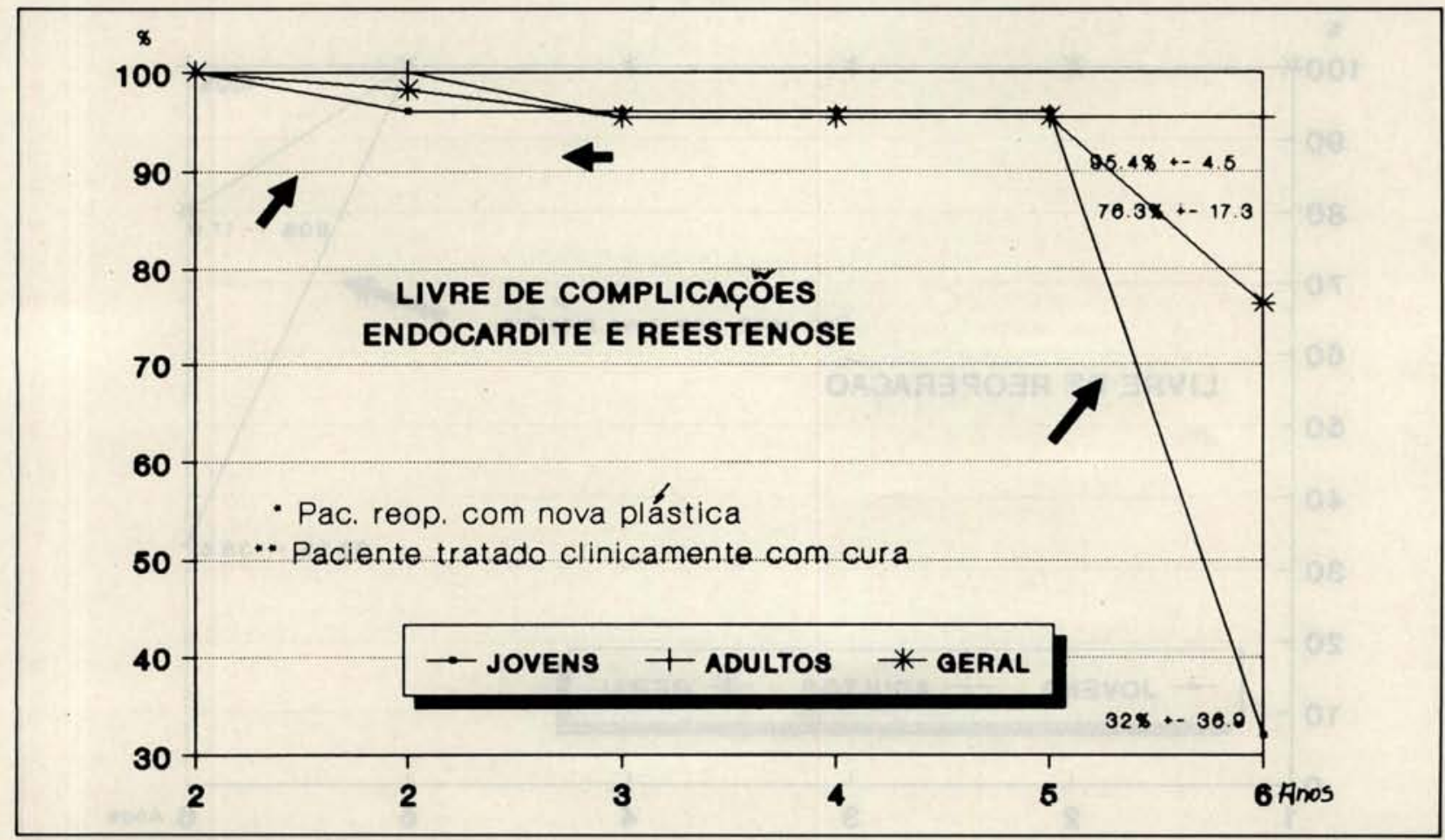


BRAILE, D. M.; ARDITO, R. V.; PINTO, G. H.; SANTOS, J. L. V.; ZAIANTCHICK, M.; SOUZA, D. R. S.; THEVENARD, R. Plástica mitral. Rev. Bras. Cir. Cardiovasc., 5(2): 86-98, 1990.

GRÁFICO 3

CURVAS ATUARIAIS DE PACIENTES SUBMETIDOS AO REPARO VALVAR LIVRES DE ENDOCARDITE EM SEIS ANOS DE SEGUIMENTO

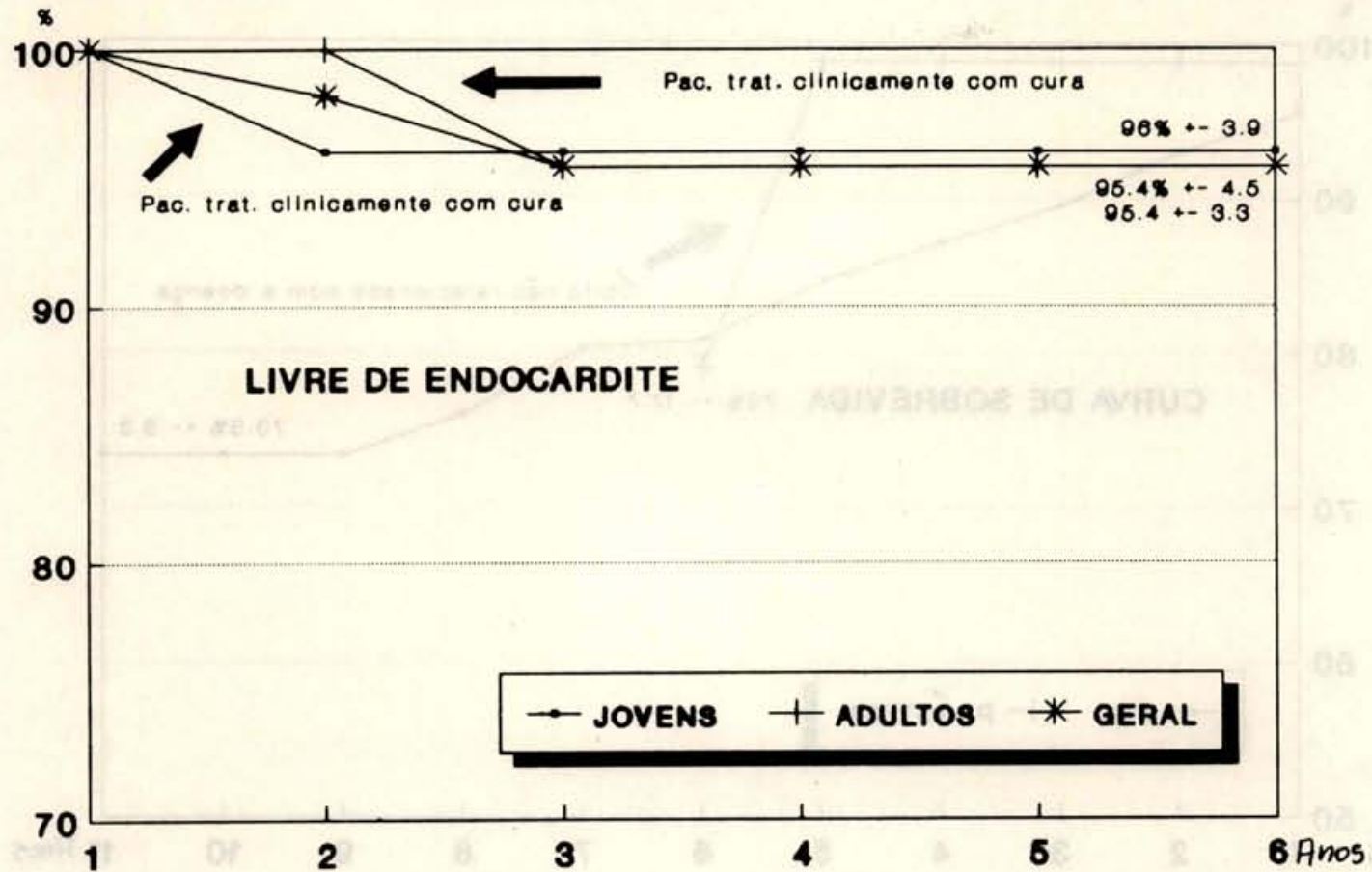

GRÁFICO 4

CURVAS ATUARIAIS DE PACIENTES SUBMETIDOS AO REPARO VALVAR LIVRES DE REOPERAÇÃO EM SEIS ANOS DE SEGUIMENTO.

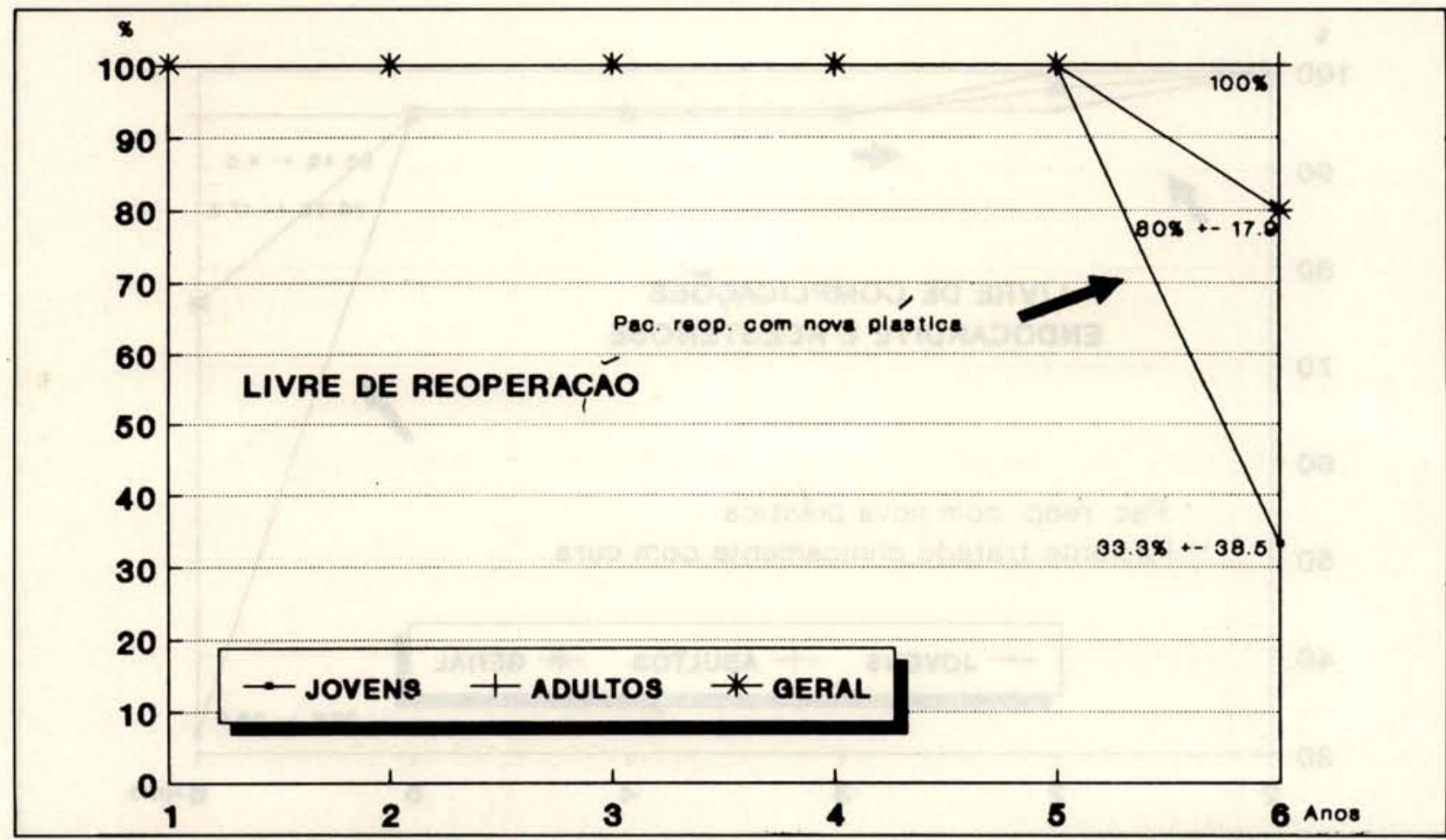


BRAILE, D. M.; ARDITO, R. V.; PINTO, G. H.; SANTOS, J. L. V.; ZAIANTCHICK, M.; SOUZA, D. R. S.; THEVENARD, R. Plástica mitral. Rev. Bras. Cir. Cardiovasc., 5(2): 86-98, 1990.

GRÁFICO 5

EVOLUÇÃO DOS PACIENTES SUBMETIDOS A CIRURGIA DE REPARO VALVAR MITRAL DE ACORDO COM A CLASSIFICAÇĀO DA NYHA EM SEIS ANOS DE SEGUIMENTO.

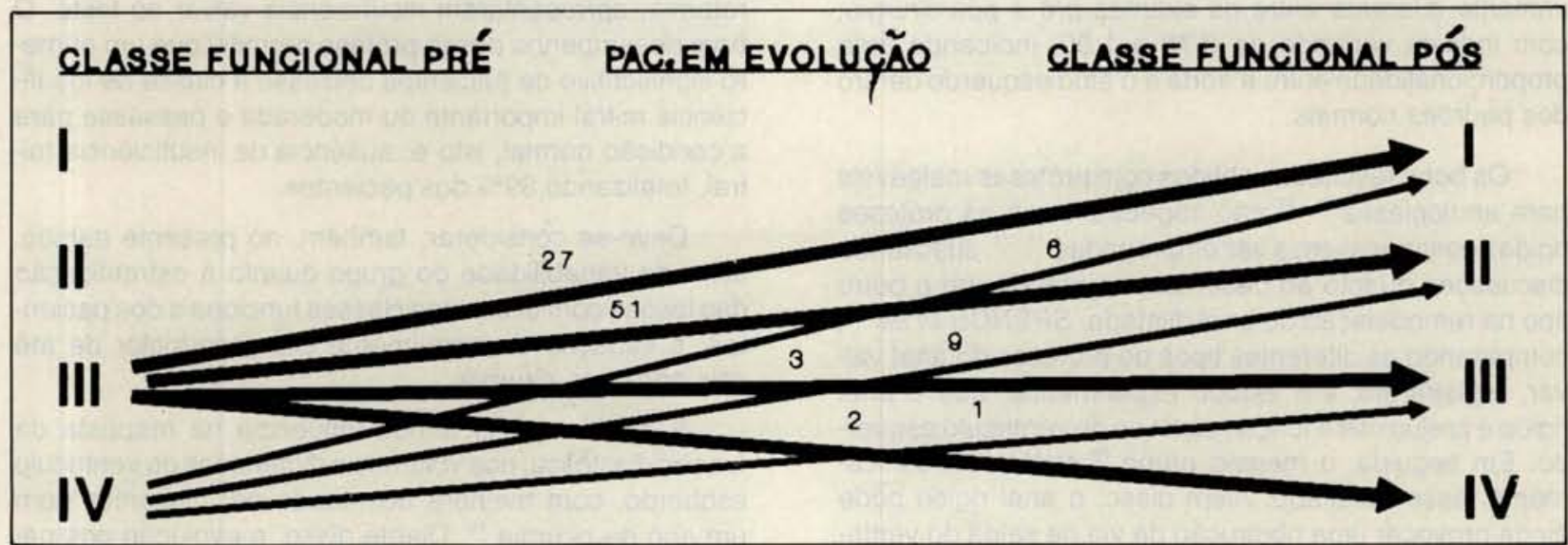

tes, quando comparada com índices relatados por outros autores $4 \cdot 6,9,20,28,30$.

O presente estudo, em $100 \%$ dos pacientes acompanhados, mostrou sobrevida de $79,0 \pm 17,7 \%$ em seis anos e $99,0 \%$ em cinco anos, satisfatória diante de $76 \%$ de sobrevida registrado por outros autores, nesse periodo ${ }^{26,38}$.

É comum encontrar referências associando os procedimentos de valvoplastia a um indice superior de sobrevida, quando comparado à troca valvar ${ }^{1}, 21,32,34,36,38$, ${ }^{40}$. No entanto, o índice de sobrevida ora apresentado (79\%) é semelhante ao índice de $80,9 \%$ para a troca mitral com prótese de pericárdio bovino no mesmo período ${ }^{6}$; é de notar diminuição do índice de reparo de $99 \%$ para $79 \%$ no quinto ano, com um óbito por AVC hemorrágico.

Quanto ao tromboembolismo, chama a atenção o índice elevado de pacientes livres desse evento, diante do reparo ou troca valvar, mesmo na ausência de anticoagulação rotineira 1 , 6, 9,11, 17, 23-26, 32, 36. Existe, também, para esses dois procedimentos, semelhança no índice de reoperação ${ }^{16,26} \mathrm{com}$ índices mais altos para reparo valvar ${ }^{1,14}$.

Houve apenas um episódio de reoperação por reagudização da doença reumática em uma jovem, no quinto ano de seguimento, com uma comissurotomia mitral, ocasionando uma redução no índice geral de reoperação de $100 \%$ para $80,0 \%$ de pacientes livres desse evento, em seis anos de seguimento. Índices da literatura variaram de 49,0 a $94,4 \%$ de pacientes livres de reoperação, diante do reparo valvar em quatro a 17 anos de seguimento. Nem sempre o menor índice esteve relacionado com o maior tempo de seguimento $2,16,26,32,38$.

$\mathrm{Na}$ decisão pela troca ou reparo valvar, é de importância fundamental a seleção adequada dos pacientes e a presença dos fatores de risco associadas ${ }^{26,38}$.
GALLOWAY et alii ${ }^{26}$, em análise multivariável combinando a idade, o sexo e os vários fatores de risco, registraram quatro elementos relacionados com o aumento de risco operatório, isto é, a idade, a classe funcional IV, a operaçāo cardiaca prévia e a performance de procedimentos cardíacos prévios. O tipo de conduta cirúrgica valvar, segundo eles, não pareceu influenciar o risco operatório ou a sobrevida tardia de pacientes com troca ou reparo valvar.

Para CARPENTIER ${ }^{12}$, a reconstrução valvar pode ser inidicada com base nas lesōes, antes mesmo de se considerar a idade, a causa da doença e a condição do paciente. Contudo, quanto mais jovem o paciente, mais urgente é a indicação para o reparo valvar.

A avaliação ecodoplercardiográfica e/ou cineangiográfica em mais de $90 \%$ dos casos ora apresentados assegurou a indicaçāo da cirurgia reparadora em pacientes em grau funcional II da NYHA, antes que tivessem maiores alteraçōes do aparelho valvar e deterioraçāo ventricular. Isso permitiu melhores resultados tardios, principalmente em crianças e jovens, pela recuperaçāo da geometria ventricular esquerda e da função mecânica da valva mitral lesada.

A plástica mitral normalmente realizada em pacientes com diagnóstico pré-operatório de insuficiência mitral ou dupla disfunção, nesse estudo, foi aplicada também em pacientes portadores de estenose mitral pura ou calcificada, após a realização de comissurotomia e/ou papilarotomia. Esse procedimento tornou-se importante na evolução pós-operatória imediata e tardia desses pacientes.

O anel maleável de pericárdio bovino implantado possibilitou, satisfatoriamente, a diminuição da área de coaptação das cúspides. Os benefícios foram evidenciados através da ecodoplercardiografia, que revelou uma reduçāo do diâmetro diastólico do ventrículo esquerdo, demonstrando melhora direta do músculo cardíaco 
com o estreitamento do anel, determinando diminuição ou ausência de regurgitação. Nesse caso, a relação entre os diâmetros da aorta e do átrio esquerdo foi significativamente diferente entre os exames pré e pós cirurgia, com índices variando de 0,78 a 1,00 , indicando uma proporcionalidade entre a aorta e o átrio esquerdo dentro dos padrōes normais.

Os bons resultados obtidos com próteses maleáveis para anuloplastia ${ }^{21,23}$ não impediram que as próteses rígidas continuassem a ser empregadas ${ }^{13,27}$, suscitando discussões quanto ao desempenho real de um e outro tipo na remodelação do anel dilatado. SPENCE et alii ${ }^{39}$, comparando os diferentes tipos de próteses do anel valvar, registraram, em estudo experimental, que o anel rígido é prejudicial à função sistólica do ventrículo esquerdo. Em seguida, o mesmo grupo ${ }^{19}$ confirmou, clinicamente, esse resultado. Além disso, o anel rígido pode ainda provocar uma obstruçāo da via de saída do ventrículo esquerdo.

$\mathrm{Na}$ escolha da prótese para o reparo valvar, parece importante considerar a etiologia da doença, de tal modo que pacientes com regurgitação mitral em decorrência de doença degenerativa, com o anel mitral contrátil, deveriam receber prótese flexível, enquanto que naqueles com regurgitação mitral reumática com o anel valvar rígido o reparo com prótese rígida ou flexível não afetaria seriamente a função ventricular esquerda. O importante é não mudar drasticamente o estado de um anel regularmente contrátil para um estado rígido ${ }^{19}$.

Em vista disso, sustentamos que o anel maleável ora apresentado, completamente biológico, restringindo-se à parte mural do anel mitral, diferindo do anel sintético flexivel descrito por DURAN \& UBAGE ${ }^{23}$, mostrou-se satisfatório em pacientes submetidos a anuloplastia pelas mais diversas causas. Entre as lesões, foram mais freqüentes aquelas provenientes da doença reumática $(77 \%)$, tendo a maioria desses pacientes anel valvar rígido. $\mathrm{O}$ alto índice de doença reumática, nesse estudo, é justificado pela inclusão de pacientes portadores de estenose mitral, que, submetidos a comissurotomia, aprresentaram insuficiência valvar ao teste. 0 bom desempenho dessa prótese permitiu que um número significativo de pacientes deixasse a classe de insuficiência mitral importante ou moderada e passasse para a condição normal, isto é, ausência de insuficiência mitral, totalizando $89 \%$ dos pacientes.

Deve-se considerar, também, no presente estudo, além da variabilidade do grupo quanto à estratificação das lesōes com diferentes classes funcionais dos pacientes, a variação do seguimento com ecodopler de até seis anos pós-cirurgia.

É sabido que o tempo influencia na resposta da função diastólica, nos volumes e dimensões do ventrículo esquerdo, com melhora acentuada em pacientes com um ano de cirurgia ${ }^{19}$. Diante disso, a evolução dos pacientes com menos de um ano de seguimento é animadora. Contudo, a situação dos pacientes reumáticos é preocupante, pois, de acordo com relatos anteriores, são os que apresentam indices mais altos de falhas ${ }^{2,12}$, 22, 26. Mesmo assim, ANTUNES et alii ${ }^{2}$ insistem em afirmar que a valvoplastia é uma excelente alternativa para pacientes jovens com doença reumática da valva mitral.

Concluindo, o anel de pericárdio bovino flexível conforma-se perfeitamente com o anel valvar, não produz hemólise, não necessita do uso de anticoagulantes e endoteliza-se completamente a médio prazo. Isso significa que o reparo da valva mitral devido a estenose, insuficiência, ou ambos oferece vantagens significativas a longo prazo, em termos de ausência de tromboembolismo, de eventos hemorrágicos relacionados a anticoagulantes. $O$ desempenho desse tipo de prótese nos convenceu de que, se o resultado hemodinâmico do paciente for inicialmente satisfatório, como sustentado por BRAIMBRIDGE et alii $^{7}$, existe a possibilidade de que persista, ao longo do tempo.

RBCCV 44205-111

BRAILE, D. M.; ARDITO, R. V.; PINTO, G. H.; SANTOS, J. L. V.; ZAIANTCHICK, M.; SOUZA, D. R. S.; THEVENARD, R. - Mitral repair.. Rev. Bras. Cir. Cardiovasc., 5(2): 86-98, 1990.

ABSTRACT: A hundred-and-one patients were studied in six years, with $100 \%$ of follow-up. Among them, 36 were male and 65 female, with an age range of two to 62 years (mean $28 \pm 16.4 \%$ ). Fifty seven of them $(56.4 \%)$ underwent just a mitral surgery, the others and other associated procedures, as tricuspid plastic $(9.9 \%)$, coronary artery revascularization $(4.0 \%)$, among others. Hospital mortality was not registered. The late mortality rate was $2 \%$ for AVC hemorrhagic after five years, and septicemia during the first year. The non-fatal complications were represented by endocarditis in two patients ( $2 \%)$, treated and cured; and a mitral restenosis after plastic. The actuarial study revealed a survival rate of $79.0 \pm$ $17.7 \%$ and rates of without complications, reoperation and thromboembolism of $76.3 \pm 17.8,80.0 \pm 17.9$ and $100 \%$, respectively. The echocardiographic results registered $89 \%$ of the patients with evolution to absence of insufficiency from the remaining $11 \%, 7.4 \%$ showed discrete mitral insufficiency, $2.4 \%$ moderate and $1.2 \%$ important. Under the NYHA classification, the patients functionally went from class III $(83.3 \%)$ and IV $(16.2 \%)$ to class I $(33.3 \%)$, II $(60.65)$, III $(4.1 \%)$ and IV $(2.0 \%)$. The authors conclude that the pericardium ring is flexible, it fits perfectly in the valvar ring, does not cause hemolysis, and shows completely endotelization after a certain time.

DESCRIPTORS: heart valves, mitral, surgery; heart valves prostheses, surgery. 
BRAILE, D. M.; ARDITO, R. V.; PINTO, G. H.; SANTOS, J. L. V.; ZAIANTCHICK, M.; SOUZA, D. R. S.; THEVENARD, R. Plástica mitral. Rev. Bras. Cir. Cardiovasc., 5(2): 86-98, 1990.

\section{REFERÊNCIAS BIBLIOGRÁFICAS}

1 ANGEL, W. W.; OURY, J. H.; SHAH, P. - A comparison of replacement and reconstruction in patients with mitral regurgitation. J. Thorac. Cardiovasc. Surg., 93: 665-674, 1987.

2 ANTUNES, M. J.; MAGALHĀES, M. P.; COLSEN, R. R. - Valvuloplasty for rheumatic mitral valve disease. J. Thorac. Cardiovasc. Surg., 94: 44-56, 1987.

3 ANTUNES, M. J.; WESSELS, A.; SADOWSKI, R. G.; SCHUTZ, J. G.; VANDERDONCK, K. M.; OLIVEIRA, J. M.; FRNANDES, L. E. - Medtronic Hall valve replacement in a third-world population group. J. Thorac. Cardiovasc. Surg., 95: 980-993, 1988.

$4 \mathrm{BLOCH}$, G.; VOUHE, P. R.; MENU, P.; POPULATION, H.; CACHERA, J. P.; AUBRY, P. H.; HEURTEMATTE, Y.; LOISANCE, D. Y.; VERNANT, P.; GALEY, J. J. - Long-term evaluation of bioprosthetic valves: 615 consecutive cases. Eur. Heart J., 5 (Supl. D): 73-80, 1984.

5 BORTOLOTTI, U.; MILANO, A.; THIENE, G.; GUERRA, F.; MAZZUCCO, A.; VALENTE, M.; TALENTI, E.; GALLUCCI, U. - Early mechanical failures of the Hancock pericardial xenograft. J. Thorac. Cardiovasc. Surg., 94: 200-207, 1987.

6 BRAILE, D. M.; BILAQUI, A.; ARDITO, R. V; GRECO, O. T.: GARZON, S. A. C.; NICOLAU, J. C.; JACOB, J. L. B.; AYOUB, J. C. A.; FEDOZZI, N. M.; ANGELONI, M. A.; LORGA, A. M. - Bioprótese cardiaca de pericárdio bovino. Arq. Bras. Cardiol., 39:247-257, 1982.

7 BRAIMBRIDGE, M. V.; MANZANERA, G.; KOSKER, S.; HUTTER, J. A. - Conservative mitral valve surgery. Thai. J. Surg., 8: 27-28, 1987.

8 BRAUNWALD, N. S. - It will work: the first successful mitral valve replacement. Ann. Thorac. Surg., 48: 51-53, 1989.

9 BRICK, A. V.; MIANA, A. A.; COLEN, E. A.; PASSOS, P. H.; BORGES, A.; JORGE, P. C.; BRAILE, D. M.; GRECO, O. T.; ARDITO, R. V.; SANTOS, J. L. V.; MAYORQUI, R. C.; LIMA, E. R.; ZAIANTCHICK, M.; CAMPOS, N. L. K. L.; GOLLARZA, H. S.; SOUZA, D. R. S.; BROFMAN, P. R.; LOURES, D. R. R.; CARVALHO, R. G.; RIBEIRO, E. J. - Seguimento de 9 anos da bioprótese valvular cardiaca de pericárdio bovino IMC-Biomédica: estudo multicêntrico. Rev. Bras. Cir. Cardiovasc., 2: 189-199, 1987

10 BRUNTON, L. - Preliminary note on the possibility of treating mitral stenosis by surgical methods. Lancet, 1: $352-356,1902$.

11 BURR, L. H.; KRAYENBUHL, C.; SUTTON, M. St. J.; PANETH, M. - The mitral aplication suture. J. Thorac. Cardiovasc. Surg., 73: 589-595, 1977.

12 CAPENTIER, A. - Cardiac valve surgery: the french correction. J. Thorac. Cardiovasc. Surg., 86: 323-337, 1983.
13 CARPENTIER, A.; DELOCHE, A.; DAUPTAIN, J. - A new reconstructive operation for correction of mitral and tricuspid insufficiency. J. Thorac. Cardiovasc. Surg., 61: $1-13,1971$.

$14 \mathrm{COHN}$, L. H. - Mitral valve surgery: reconstruction versus replacement. Presented at the International Symposium Advances in Cardiology - Controversial Views, Berlin, West Germany, 1984. (Resumos).

15 COOLEY, D. A. - Technical problems in mitral valve repair and replacement. Ann. Thorac. Surg., 48: 591-592, 1989.

16 COSGROVE, D. M. - Mitral valve repair in patients with elongated chordae tendineae. J. Cardiac. Surg., 4: 247-252, 1989.

17 Cosgrove, D. M.; CHANZ, A. M.; LYTLE, B. W. - Results of mitral valve reconstruction. Circulation, 74 (Supl. 1): 82-87, 1986.

18 COSGROVE, D. M. \& STEWART, W. J. - Mitral valvuloplasty. Current Probl. Cardiol., 21: 81,86, 1989

19 DAVID, T. E,; KOMEDA, M.; POLLICK, C.; BURNS, R. J. - Mitral valve annuloplasty: the effect of the type on left ventricular function. Ann. Thorac. Surg., 47: 524-528, 1989.

20 DISESA, U. J.; COHN, L. H.; COLLINS Jr., J. J.; KOSTER Jr., J. K.; VANDEVANTER, S. H. - Determinants of operative survival following combined mitral valve replacement and coronary revascularization. Ann. Tho. rac. Surg., 34: 482-489, 1982.

21 DURAN, C. G.; POMAR, J. L.; REVULETA, J. M. - Conservative operation for mitral insufficiency critical analysis supported by postoperative hemodynamic studies of 72 patients. J. Thorac. Cardiovasc. Surg., 79: 326-337, 1980.

22 DURAN, C. G.; REVUELTA, J. M.; GAITE, L. - Stability of mitral reconstructive surgery at 10-12 years for predominantly rheumatic valvular disease. Circulation, 78 (Supl. 1): 91-96, 1988.

23 DURAN, C. G. \& UBAGE, J. L. M. - Clinical and hemodynamic performance of a totally flexible prosthetic ring for atrioventricular valve reconstruction. Ann. Thorac. Surg., 22: 458-465, 1976.

24 GALlOWAY, A. C.; COLVIN, S. B.; BAUMANN, F. G. Current concepts of mitral valve reconstruction for mitral insufficiency. Circulation, 78: 1087-1098, 1988.

25 GALLOWAY, A. C.; COLVIN, S. B.; BAUMANN, F. G. Long-term results of mitral valve reconstruction with Carpentier techniques in 148 patients with mitral insufficiency. Circulation, 78 (Supl. 1): 97-105, 1988.

26 GALLOWAY, A. C.; COLVIN, S. B.; BAUMANN, F. G.; GROSSI, E. A.; RIBAKOVE, G. H.; HARTY, S.; SPENCER, F. C. - Comparison of mitral valve reconstruction with mitral valve replacement: intermediate-term results. Ann. Thorac. Surg., 47: 655-662, 1989. 
BRAILE, D. M.; ARDITO, R. V.; PINTO, G. H.; SANTOS, J. L. V.; ZAIANTCHICK, M.; SOUZA, D. R. S.; THEVENARD, R. Plástica mitral. Rev. Bras. Cir. Cardiovasc., 5(2): 86-98, 1990.

27 GROGORI, F.; SILVA, S. S.; BABA, K.; QUEIROZ, L. T.; TAKEDA, R.; FACANHA, L. A.; SHIGUERU, S.; CANESIN, O. - Um novo modelo de anel protético para pacientes com insuficiência valvar mitral: relato de dois casos. Arq. Bras. Cardiol., 50: 417-420, 1988.

28 IONESCU, M. I.; SILVERTON, N. P.; TANDON, A. P. The pericardial xenograft valve in the mitral position. In: IONESCU, M. I. \& COHN, L. H. - The mitral valve disease. Boston, Butterworth \& Co., 1985. p. 253-269.

29 LILLEHEI, C. W.; GOTT, V. L.; DeWALL, R. A. - Surgical correction of pure mitral insufficiency by annuloplasty under direct vision. Lancet, 77: 446-450, 1957.

30 MAGILLIGAN Jr., D. J.; LEWIS Jr., J. W.; JARA, F. M. - Spontaneous degeneration of porcine xenografts. Annual Meeting of the Society of Thoracic Surgeons, Atlanta, GA, 1980. (Resumo).

31 MURPHY Jr., J. P.; SWEENEY, M. S.; COOLEY, D. A. - The Puig-Massana-Shiley annuloplasty ring for mitral valve repair: experience in 126 patients. Ann. Thorac. Surg., 43: 52-58, 1987.

OKITA, Y.; MIKI, S.; KUSUHARA, K.; UEDA, Y.; TAHATA, T.; TSUKAMOTO, Y.; KOMEDA, M.; YAMANAKA, K.; SHIRAISHI, S.; TAMURA, T.; TATSUTA, N.; KOIE, $H$. - Early and late results of reconstruction operation for congenital mitral regurgitation in pediatric age groups. J. Thorac. Cardiovasc. Surg., 96: 294-298, 1988.

33 OLESEN, K. H.; RYGG, I. H.; WENNEVOLD, A.; NYBOE, J. - Long-term follow-up in 185 patients after mitral valve replacement with the Lillehei-Kaster prosthesis: overall results and prosthesis-related complication. Eur. Heart J., 8: 680-688, 1987.

34 PERIER, P.; DELOCHE, A.; CHAUVAUD, S. - Comparative evaluation of mitral repair and replacement with Starr, Björk and porcine valve prostheses. Circulation, 70 (Supl. 1): 187-192, 1984.

35 PERLOFF, J. K. \& ROBERTS, W. C. - The mitral apparatus functional anatomy of mitral regurgitation. Circulation, 46: 227-239, 1972.

36 PLUTH, J. R. - Mitral valve reconstruction versus prosthetic valve replacement. In: McGOON, D. C. (ed.) Cardiac surgery. 2. ed. Philadelphia, F. A. Davis, 1987. p. 127-139.

37 REUL, G. J.; COOLEY, D. A.; DUNCAN, J. M.; FRAZIER, O. H.; HALLMAN, G. L.; LIVESAY, J. J.; OTT, D. A.; WALKER, W. E. - Valve failure with the lonescu-Shiley bovine pericardial bioprosthesis: analysis of 2680 patients. J. Vasc. Surg., 2: 192-204, 1985.

38 SAND, M. E.; NAFTEL, D. C.; BLACKSTONE, E. H.; KIRKLIN, J. W.; KARP, R. B. - A comparison of repair and replacement for mitral valve incompetence. $J$. Thorac. Cardiovasc. Surg., 94: 208-219, 1987. a better understanding of the etiology of left ventricular dysfunction after mitral valve replacement: an experimental study with possible clinical implications. Ann. Thorac. Surg., 41: 363-371, 1986.

40 SPENCER, F. C.; COLVIN, S. B.; CULLIFORD, A. T.; ISON, O. W. - Experiences with the Carpentier techniques of mitral valve reconstruction in 103 patients (1980-1985). J. Thorac. Cardiovasc. Surg., 90: 341-350, 1985.

41 STARR, A. \& EDWARDS, M. C. - Mitral replacement: clinical experience with a bal valve prosthesis. Ann. Surg., 154: 726-729, 1961.

AGRADECIMENTO: Este trabalho foi desenvolvido com a colaboração da Divisão de Pesquisas e Publicaçōes (DPP) da IMC-Biomédica de São José do Rio Preto.

\section{Discussão \\ DR. ALEKSANDER DOBRAIANSKYJ}

Goiânia, GO

Primeiramente, gostaríamos de parabenizar o $\mathrm{Dr}$. Braile e seus colaboradores, pela excelência do trabalho realizado e pela originalidade do procedimento. Também se deve ressaltar que o $\mathrm{Dr}$. Braile, desenvolveu e aperfeiçoa próteses biológicas de pericárdio bovino, há longos anos. $\mathrm{E}$ isso, por si, mostra o valor deste trabalho de desenvolvimento na sua instituição (IMC), em que se preza pela conservação do aparelho valvar mitral (AVM), que recebe a nossa simpatia, por concordarmos amplamente com esse procedimento. Por todos nós, é conhecido e bastante debatido o desempenho dos pacientes valvares mitrais em que se realiza comissurotomia versus substituição valvar, com ressecção de todo AVM original. Os desempenhos pós-operatório imediato e tardio são totalmente favoráveis para o processo conservativo mitral. Autores, como o Dr. Tirone David, do Canadá, têm demonstrado que a conservação de parte ou do todo do AVM, no caso de implante de prótese, mostra um desempenho hemodinâmico superior à ressecção total do AVM, com menor mortalidade. Ressalte-se que o mesmo Dr. David, mais recentemente, referendou o mesmo para procedimentos de conservação de todo AVM, utilizando-se diferentes técnicas, também chamadas de plastia mitral. Para nós, tem sido, há vários anos, nítida a superioridade dos processos conservativos sobre a troca valvar, onde predomina menor taxa de mortalidade, menos síndrome de baixo débito pós-operatória, melhor funçāo ventricular, menor incidência de tromboembolismo e endocardite bacteriana. As desvantagens seriam a insuficiência mitral residual ou estenose e a importância da "curva de aprendizado" para o procedimento. Para tanto, utilizamos a classificação de Carpentier, com três tipos de comportamento dos folhetos mitrais; Tipo 1) movimentação normal dos folhetos (lesão: dilatação do anel ou perfuração); Tipo 2) prolapso dos folhetos por: rotura de cordoalhas ( $\mathrm{m}$. papilares de alon- 
BRAILE, D. M.; ARDITO, R. V.; PINTO, G. H.; SANTOS, J. L. V.; ZAIANTCHICK, M.; SOUZA, D. R. S.; THEVENARD, R. Plástica mitral. Rev. Bras. Cir. Cardiovasc., 5(2): 86-98, 1990.

gamento das cordoalhas ou $\mathrm{m}$. papilares);Tipo 3) restrição à mobilidade dos folhetos (por: fusão comissural ou cordoalhas e espessamento dos folhetos ou cordoaIhas). Para isso, a boa técnica de plastia deve ser estandartizada reprodutivel e ter bons resultados a longo prazo. Como o Dr. Braile, ressaltamos as vantagens da anuloplastia flexivel, um dos procedimentos sobre AVM, pois o implanté e o ajuste são facilitados não obstruem a via de saída de VE (como o anel rígido) o formato modifica-se com o ciclo cardíaco e a função ventricular sistólica é aumentada em relação ao anel rígido. Mas nós gostariamos de realçar que, para pacientes com ânulos mais rígidos e idade acima de 21 anos, preferimos o anel completo (fechado tipo Duran), ao invés do anel aberto (tipo Braile, ou De Vega), pois nos parece que a conformação do ânulo mitral fica melhor assegurada e nesses casos o paciente não está mais em crescimento. No nosso material e idade abaixo de 21 anos, figuram $54 \%$ dos pacientes ( 24 em 44 pacientes), sendo que temos quatro lactentes. $O$ encurtamento de cordas e cordoalhas + plicatura e/ou ressecção de parte dos folhetos + comissutoromias e/ou papilarotomia foram realizadas em $72 \%$ dos pacientes e anuloplastia de Duran foi realizada em 10 pacientes, De Vega em 22 pacientes e Braile em 2 pacientes. Realizamos um quadro comparativo entre o grupo do IMC de São José do Rio Preto e o nosso de Goiânia, onde ressaltamos o ocorrência maior de pacientes jovens e a freqüencia de plastias ser o dobro da do Serviço do Dr. Braile, pois insistimos nesse procedimento sempre que possivel, principalmente nesse grupo etário. Concluímos perguntando se: 1) a possibilidade do anel tubular de pericárdio bovino-Braile (PTP-B) ter sua longitude aumentada para $15 \mathrm{~cm}$ (para uso com anel de Duran) e menor diâmetro para uso em crianças, que notamos no ecocardiograma de controle e no implante ser algo redundante; 2) já utilizaram os autores em valvuloplastia tricúspide? 3) há, em algum acompanhamento de paciente jovem, alguma evidência de calcificaçāo? 4) utilizam os autores antiadesivos plaquetários no pós-operatório tardio? 5) têm alguma avaliaçāo intra-operatória instrumental, como ecodoppler e fonocardiograma?

RENATO A. K. KALIL Porto Alegre, RS

Agradecemos à Comissão Organizadora o privilégio do convite para realizar este comentário e cumprimentarmos os autores pela apresentaçāo. Os benefícios da valvoplastia na insuficiência mitral têm sido reconhecidos por número crescente de cirurgiões e a realização de procedimentos reconstrutivos mitrais tem sido prática corrente em diversos centros. A preservação do aparelho valvar está associada a menor mortalidade hospitalar, maior sobrevida tardia e melhores resultados funcionais, que conferem melhor qualidade de vida aos pacientes, particularmente quando, como ocorre entre nós, essa enfermidade prevalece em pessoas jovens e do sexo feminino. Discute-se hoje sobre qual a técnica preferida para reconstrução valvar. Ressalvadas as situaçōes de rotura ou alongamento de cordoalha, ou ainda de disfunçāo de músculo papilar, na nossa experiência, a grande maioria das regurgitações se devem à dilatação do anel valvar. Sabemos que a porção fibrosa do anel não é passivel de dilataçāo, o que se dá sempre às custas da distensão do folheto mural ou posterior. Baseadas nessa premissa, todas as técnicas descritas de anuloplastia visam à redução do comprimento do folheto mural, seja sem suporte protético, como proposto por Wooler, Kay e Reed, entre outros, ou com suporte por anel rígido de Carpentier, ou flexíveis de Duran, Puig-Massana e outros, ou simples barras de suporte do folheto posterior, como tem sido proposto mais recentemente. Todos os métodos, repetimos, visam à redução do comprimento do folheto posterior, diminuindo a circunferência do orifício valvar para obter a aposição e competência dos folhetos. Os resultados, em geral, sāo superponiveis, com qualquer dessas técnicas de anuloplastia. Pelas razōes expostas, temos optado, desde 1974, pela técnica de Wooler modificada, que consiste na simples plicatura do folheto posterior, respeitando a amplitude do foIheto septal ou anterior. Nossos resultados têm sido apresentados em eventos no exterior, bem como nos congressos da Sociedade Brasileira de Cardiologia, divulgados no meio universitário e publicados nos "Arquivos Brasileiros de Cardiologia". A experiência inicial foi apresentada neste Congresso Nacional de Cirurgia Cardiaca, em 1980. Recentemente, fizemos a reavaliação dos resultados tardios em grupo de 50 pacientes com seguimento mínimo de cinco anos e máximo de 15 anos. A propabilidade de sobrevida foi de $79 \pm 6 \%$ no 7 : ano e de $74 \pm 7 \%$ no 15 : ano. Pacientes livres de eventos foram $58 \pm 7 \%$ aos 7 anos e $44 \pm 8 \%$ aos 15 anos. $\mathrm{Na}$ última avaliação, $83 \%$ dos pacientes estavam em classes funcionais I e II. Esses resultados comparam-se favoravelmente a outras séries submetidas a implante de anéis de Carpentier, como na Universidade de Alabama, bem como é nitidamente superior aos resultados de próteses biológicas a longo prazo, como se vê em relatos recentes. Pelas razões citadas, pensamos ser preferivel o emprego de anuloplastias simples, chamadas de Wooler, Reed ou Kay, pela evidente maior rapidez e simplicidade de execução, tendo em vista serem comparáveis os resultados tardios ao emprego de anéis ou barras de suporte. A experiência apresentada pelos autores, propondo o emprego de barra de pericárdio bovino, traz a contribuição deste material em mais uma utilização, entre as muitas já difundidas em cirurgia cardiaca. O acompanhamento a médio prazo mostra bom resultado. Preocupa, entretanto, a evolução após o quinto ano, pois poderá haver uma queda significativa na sobrevida, quando maior número de casos alcançar esse prazo pós-operatório. Relatam os autores a extensāo do emprego da barra de pericárdio bovino a pacientes com estenose mitral pura em 20 casos ( $19,8 \%$ da série), cuja necessidade não compreendemos, pois não ficou evidente a importância desse procedimento em casos de estenose mitral pura ou calcificada, como se afirmou. 

Plástica mitral. Rev. Bras. Cir. Cardiovasc., 5(2): 86-98, 1990.

Cabe aqui uma palavra de cautela, em relação ao extenso uso de pericárdio bovino para várias finalidades. A facilidade do manuseio e sua fácil obtenção tornam o material especialmente atraente ao cirurgião. Entretanto, sabemos ser o mesmo passível de fibrose e aderência extensa (como na substituição de pericárdio em reoperaçōes), ou degeneração com rotura ou calcificação, ou ainda na formação de espessa neoíntima obsrutiva, como observamos em cirurgia de Mustard, em nossa experiência e em relatos da literatura. A proposta de emprego como barra de suporte ao anel mitral pode se mostrar útil em determinadas situações. Entretanto, os resultados da série apresentada nos parecem insuficientes para tornar segura sua recomendação para valvoplastia mitral. Mais extensa observação se faz necessária para tal fim.

\section{DR. BRAILE \\ (Encerrando)}

Agradeço os comentários dos colegas Aleksander Dobrianskyj e Renato Kalil que, sem dúvida, vieram enriquecer nosso trabalho, assim como suscitar dúvidas pertinentes. Respondendo ao Dr. Dobrianskyj, posso assegurar que existe a possibilidade de fazer uma prótese de pericárdio bovino com $15 \mathrm{~cm}$ de comprimento, assim como não há nenhuma dificuldade em fazê-las mais estreitas para uso em crianças, o que, tenho certeza, é uma boa idéia e uma contribuição, a qual agradeço. Em relação à plástica da valva tricúspide, devo afirmar que temos usado a mesma prótese e uma técnica bastante semelhante com pontos separados na parte ânterosuperior do anel, que são passados na prótese tubular de pericárdio bovino, cujo comprimento é selecionado de acordo com a medida obtida com os mesmos medidores que descreveremos para a plástica mitral. Não encontramos, até o momento, qualquer sinal de calcificação, mesmo nos pacientes jovens; quanto a isso, não temos maior preocupação, pois sabemos que o processo de deposiçāo do cálcio está relacionado ao stress, que é muito pequeno neste caso; além do mais, nāo me parece que sua ocorrência possa levar a alguma complicação maior. Temos utilizado antiadesivos plaquetários (aspirina) apenas nos primeiros três meses após a plástica; no caso das substituiçōes valvares mantemos a droga indefinidamente. Com relação à avaliação intra-operatória da válvula mitral, tem sido realizada com a introdução de uma cânula plástica $12 \mathrm{~F}$ através da válvula aórtica, enchendo-se o ventrículo esquerdo com sangue proveniente do circuito de bombeamento da cardioplegia, o que nos permite avaliar estaticamente a continência da válvula. Esse método me parece adequado e tem dado bons resultados; não coloco, contudo, em dúvida que 0 uso do ecocardiograma intra-operatório possa nos auxiliar ainda mais na avaliação da performance dinâmica da válvula. Respondendo aos comentários do Dr. Kalil, tenho que concordar com ele em que todas as técnicas de reconstrução da válvula mitral podem levar a bons resultados, desde que bem indicadas e realizadas por quem as domine. Não tive, na apresentação do trabalho, qualquer intenção de inventar algo novo, apenas mostrar mais uma técnica que tem levado a bons resultados e que me parece mais fácil tecnicamente e também de custo compatível com nossa economia. Tenho que me penitenciar, por não ter citado, nas referências bibliográficas, os trabalhos do $\mathrm{Dr}$. Kalil, e a única explicação para o fato decorre da busca realizada, que se baseou nas próteses para reconstrução do anel mitral. A longa experiência que temos tido com o uso do pericárdio bovino nas mais diferentes posiçōes pode nos assegurar do seu uso a longo prazo. Os 20 casos de estenose mitral pura em que empregamos a técnica talvez representou uma importante contribuição do nosso trabalho, uma vez que, após a comissurotomia, verificou-se o aparecimento de insuficiência mitral importante com indicação de troca valvar, que foi evitada com a correçāo da distorção do anel da valva. A técnica tem sido incorporada por muitos grupos cirúrgicos, pela facilidade de sua realização e pelos bons resultados apresentados. 